\title{
Free Estradiol to Estradiol Ratio Measurement
}

National Cancer Institute

\section{Source}

National Cancer Institute. Free Estradiol to Estradiol Ratio Measurement. NCI Thesaurus. Code C150843.

The determination of the ratio of free estradiol compared to total estradiol present in a sample. The measurement may be expressed as a ratio or percentage. 